\title{
Brand Equity: \\ Can There Be Too Much Of A Good Thing?
}

Alexander Rusetski, York University, Toronto, Canada

\begin{abstract}
While academic research focuses almost solely on the positive effects of brand equity, numerous instances of the decline and failure of once-strong brands suggest the existence of another category of effects that may offset the positive ones. This paper suggests that an inquiry into the negative effects of brand equity is required to complement and enhance our existing knowledge. Evidence of the decline of strong brands from the literature is presented, and a set of research directions and testable propositions is suggested that should allow quantifying the possible negative effects of brand equity.
\end{abstract}

Keywords: Brand Equity; Brand Management

\section{INTRODUCTION}

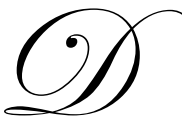

ecisions based on incomplete models of reality can potentially have catastrophic results. People tend to construct simplified models with linear cause-and-effect associations (e.g., "the more of $\mathrm{X}$ - the better the Y"), ignoring the possibility of feedback and multiple multidirectional relationships. All too often, such simple, reductionist models have led to decisions that heavily emphasized just a few factors, resulting in completely unintended and sometimes disastrous outcomes - from as earth-shattering as revolutions to as mundane as corporate scandals (Dorner 1996).

Due to the demand for methodological rigor, science in general, and social sciences in particular, must rely on reductionist models when studying complex causal chains. And while a general understanding of the full chain of relationships is almost always embedded in the field, it is not unusual to see the bulk of empirical work focus almost exclusively on a particular part of the chain.

The branding and brand equity streams are good examples of such a tendency. The bulk of empirical studies in these fields focuses almost exclusively on the positive effects of brand equity on a brand's market performance. In a very simplistic form, the argument can be presented that the stronger the brand equity, the better are the chances for an existing product to be re-purchased and for a new product to be tried and received positively by consumers (see Keller 2002 for a review of the literature). This will lead to better financial performance of a brand; increased sales combined with positive customer experience, especially repeated experience, in turn, will lead to a further increase of brand equity (Oliver 1999), and the cycle will go on and on - a typical "the more - the better" kind of model suggesting an unbreakable upward spiral for brand equity, steeper for stronger brands (Figure $1)$.

Yet, with recent decline of such iconic brands as Xerox, Polaroid or Kodak and many others it is obvious that strong brand are not completely immune from perils of the market. One can easily come up with stories of market leaders not only losing their leading positions but even disappearing completely (for some examples see Golder 2000, Haig 2003). Strong brands' failures suggest the possibility of negative effects associated with strong brand equity which, if not managed appropriately, may cancel out or overcome the positive effects so richly addressed in empirical studies. In other words, along with numerous benefits, strong brand equity must carry with it seeds of its own destruction. For instance, strong brands become increasingly difficult to reposition; the costs of branding errors and product failures magnify greatly because of the strong brand's visibility; the high expectations of consumers and stakeholders put additional pressure on brand managers, which can in turn, lead to more suboptimal decisions, etc. 


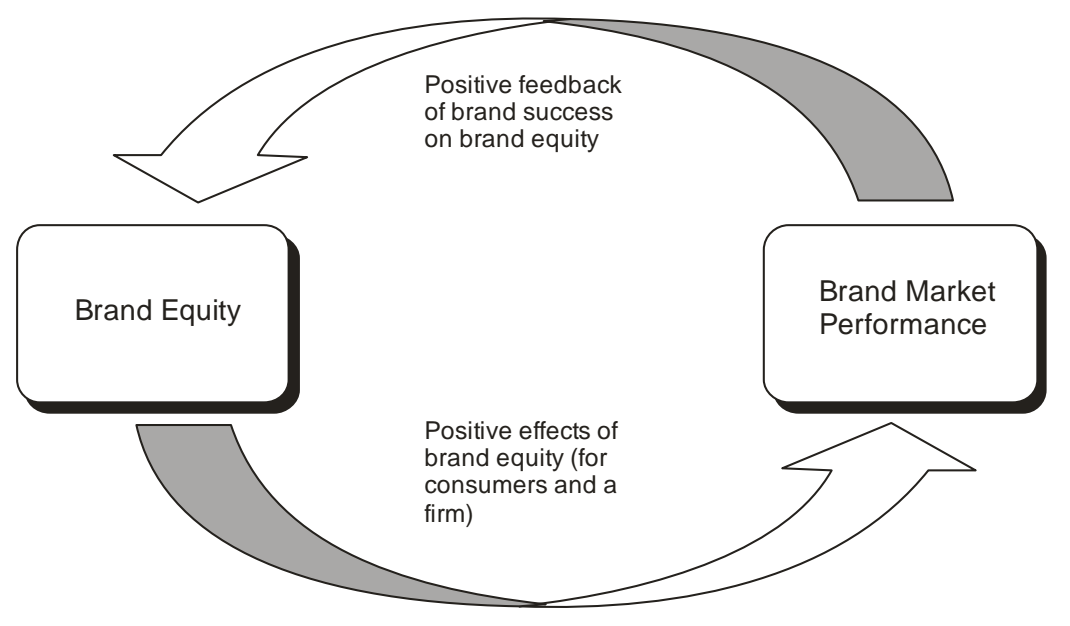

Figure 1: Current representation of brand equity effects in the academic literature.

Ignoring the negative effects of brand equity create a significant gap both in academic research and in managerial practice. From an academic standpoint, study of the negative effects of brand equity can complement existing models, making them more realistic and enabling them to explain more variance in brand performance. Financial models can be further enhanced by more precise estimates of risk factors to discount future cash flows (Schultz 2000). From the practitioners' point of view, knowledge of the potential antecedents and moderators of brand equity's negative effects can inform strategic decisions, making it possible to adjust branding activities before decline becomes catastrophic.

This paper is motivated by the question "Why do strong brands fail?" and its central idea is that brand equity effects are not invariably positive. The purpose of this paper is to encourage a new direction in brand equity research that will look into the negative effects of brand equity, investigating variables that intensify or attenuate them.

The rest of the paper is organized as follows: first, I review brand equity effects currently reflected in empirical studies. I then present available evidence of the susceptibility of strong brands to failure. Following this, and along the major research directions pursued in brand equity studies, I develop testable propositions that may provide insights into the negative effects of brand equity.

\section{BRAND EQUITY EFFECTS}

Although no uniform conceptualization of brand equity exists (Keller 2002, Fieldwick 1996, Woods 1998), in this paper I rely on Keller's $(1993,2002)$ definition of customer-based brand equity as "the differential effect of brand knowledge on consumer response to the marketing of the brand" (Keller 1993, p. 2). I also use the term "strong brand" as equivalent to a "brand with strong brand equity".

Routinely acknowledging the "fragility" of the brand equity, existing empirical literature is almost unanimous in describing its positive aspects. The review by Keller (2002) identifies the following effects of a strong brand:

- $\quad$ it improves the probability of a product being included in a consideration set;

- $\quad$ it improves consumer's evaluation of the product;

- $\quad$ it improves consumer's perception of product quality;

- $\quad$ it increases consumers preference and purchase intention;

- $\quad$ it mitigates the effect of a negative trial;

- $\quad$ it enables to command price premium; 
- $\quad$ it is relatively immune to price competition;

- $\quad$ it has better chances to survive product-harm crises.

From other publications it follows that stronger brand equity:

- $\quad$ affects a brand's ability to maintain its choice share in the face of trivial differentiation by other members of the same product category;

- $\quad$ attenuates the likelihood of consumer's negative inferences about the firm's motives following a price increase;

- mitigates the effect of negative information (Broniarczyk and Gershoff 2003, Campbell 1999, Ahluwalia, Burnkrant, and Unnava 2000).

The above advantages should practically guarantee the success and survival of strong brands, and in many cases it really happens. Notice, though, that virtually no studies address situations where a brand with strong equity will be at a disadvantage compared to a brand with weaker equity. Such situations are discussed in textbooks, but no attempts have been made to empirically investigate and quantify factors that drive them. This creates an impression that empirical research virtually denies brand failure, or at least fails to explain it.

\section{BRAND DECLINE AND FAILURE}

There exists a plethora of anecdotal evidence of erstwhile market leaders losing their positions quickly and often disappearing completely. Interbrand's "The 100 Top Brands" list published annually by Business Week since 2000 provides some vivid examples. The immense popularity enjoyed by the Compaq brand has been reflected in its monetary value estimates: in 2000 it was number 21 among the world's top brands reported by Interbrand, with an estimated $\$ 14.6$ billion attached to its name. A shift in channel preferences sent the company into a tailspin, and you will not find Compaq in the 2003 "The 100 Top Brands" list. AT\&T, the number 10 brand in 2001 with estimated value of $\$ 22.8$ billion did not make it into the 2003 list (where the number 100 brand had a value of $\$ 1.61$ billion). Texas Instruments, number 64 in 2001 with $\$ 4.04$ billion brand value never appeared in later lists. Hilton and Pampers, brands that were close to the bottom of the 2001 list, could not keep up with other brands and were squeezed out of the list by brands with larger values, just like 3M that briefly made it to the 2002 list. In 2010, safety problems with Toyota cars cost the brand $16 \%$ of its value ( $\$ 5.14$ billion) and 3 spots in the ranking - all over just a single year. Between 2008 and 2010, large diversified electronics manufacturer SONY moved down nine positions in the ranking losing $16.4 \%$ of its value. These brands did not leave the market entirely, but the speed with which they lost their positions is surprising and contradicts the "the-more-the-better" model. And note, that Interbrand's lists include cream of the crop brands with estimated individual values not less than $\$ 1$ billion!

Interbrand's ranking is based on monetary value estimates. Using a market outcome measure of brand strength (market share), Golder (2000) demonstrated that by 1996, 77\% of brands that were number 1 in 1923 lost their leading positions, with $23 \%$ disappearing from the market completely. Thirty five percent of the brands that were among the top five in their categories in 1923 did not survive. For the durables the rates were even more pessimistic: $42 \%$ of number one brands and $45 \%$ of top five brands left the market by 1996 . This mortality does not fit well with all of the positive effects found in academic research on strong brand equity (it is also interesting to note that the mortality of firms that were number 4 and number 5 in 1923 is smaller than that of the higher ranked firms).

No matter how brand equity is defined and measured - in terms of monetary value or market performance the evidence shows that contrary to established beliefs, strong brands do lose their leadership, and sometimes may not recover after such a loss, leaving the market completely. This seems intuitively appealing - a strong brand is not a panacea for all problems and not a sorcerer's stone, but an asset that just like other assets should have both positive and negative sides to it. The task is to find a systematic way to study both. 


\section{THE NEGATIVE EFFECTS OF BRAND EQUITY: A TENTATIVE FRAMEWORK}

Studying the adverse effects of brand equity should proceed along the same general lines used to study its positive effects (Figure 2).

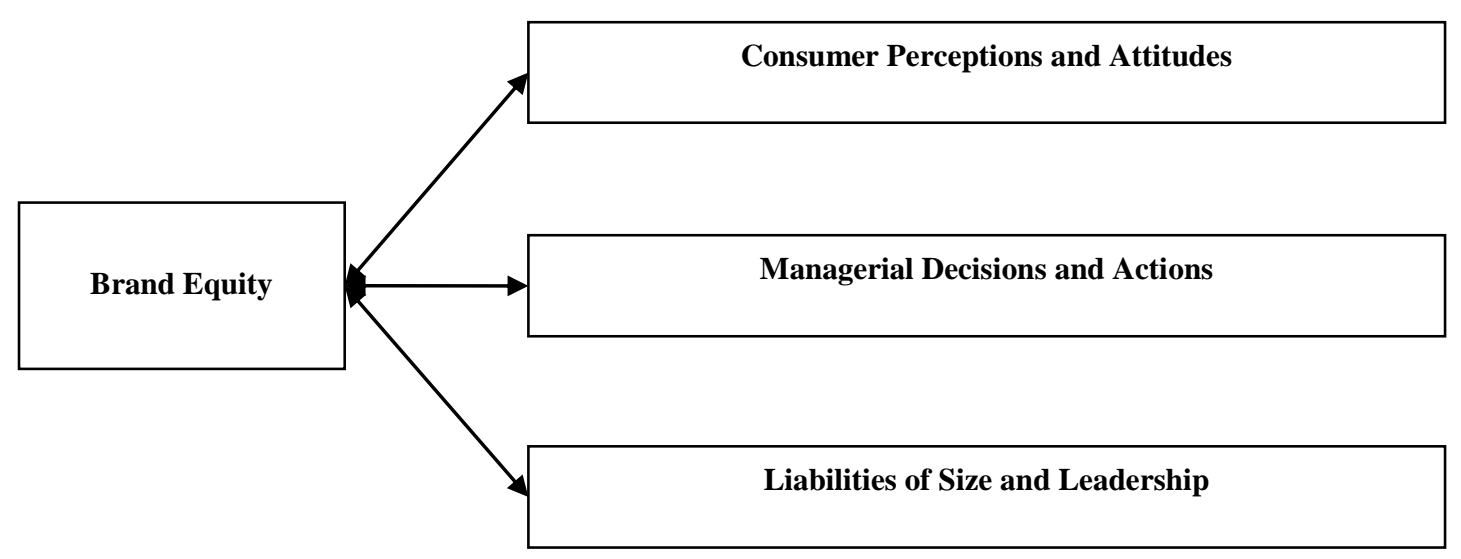

Figure 2: Areas of possible brand equity negative effects

Extant literature demonstrates that strong brand equity can and does influence consumer perceptions and attitudes. I suggest that the outcome of such influence may not be strictly positive.

It has been shown that managerial decisions and actions often deviate from optima, being driven not only by objective inputs but also by the idiosyncrasies of managers and by change in psychological states. I propose that those states can be influenced by the strength of the brand's equity, causing risk-averse or risk-tolerant behaviors as opposed to balanced strategies.

Growth and the acquisition of market share are valid goals for brand-building. Yet a brand's size and the fact that it leads the market can limit the ability of a brand to reinvent itself and exert a pressure on decisionmakers.

It needs to be noted that while managerial decision making is within top management's direct control, consumer perceptions and market events can be influenced by a firm only indirectly and to a lesser degree.

Next I will examine possible directions of study along these lines.

\section{Consumer's Perceptions of a Brand}

I base the following discussion on Keller's (1993) typology of consumer-based assets comprising brand equity, i.e. brand awareness, brand familiarity, and brand associations. Increasing each of them leads to improved brand equity overall. But what could be the side effects of an overzealous emphasis being placed on the growth of consumer-based brand assets? I suggest taking another look at several streams investigating the nature of consumerbased assets: customer expectations, customer satisfaction, and perceptions of fairness.

\section{Expectations mismanagement}

To choose a product from a consideration set, a customer needs verifiable information on attributes that are not readily observable. If only information about a weaker brand's attributes is available, better attributes will be inferred for a product with a stronger brand (Purohit and Srivastava 2001). Although this inference may prove true, if it bears out as incorrect and consumers are dissatisfied, they (consumers) may be expected to place the blame on 
the manufacturer for providing an inadequate product (or information - c.f. Spreng, Mackenzie, and Olshavsky 1996), rather than placing the blame on themselves for making wrong inferences. Attribution theory (Weiner 2000) supports this expectation, as people tend to make external attributions in cases of failure (in our case - in case of disappointing performance) as opposed to internal attributions in case of success (self-serving bias - e.g. Sujan 1986). Therefore, building brand awareness and brand associations will carry the risk of uncontrolled growth in performance expectations that may, if those expectations are not met, result in consumer dissatisfaction and the blame being placed on the brand.

P1: Failure of a product to meet inferred characteristics will be blamed by a customer on a brand rather on herself.

The process involved here is more dangerous than the loss of credibility implied by the signaling approach to brand equity (Erdem and Swait 1998, Rao, Qu, and Ruekert 1999, Kirmani and Rao 2000): the firm (brand) does not necessarily need to be involved in transmitting any misleading signals at the point of purchase to be blamed by the customer. Unrealistic expectations can be prompted by competitors' advertising, by word of mouth or even by previous experiences with other products of the same brand. Also, for inflated expectations to harm brand equity the actual performance may not necessarily be poor compared to other products in the same category. If a comparison of expectations and actual performance is easy and unambiguous, dissatisfaction can occur without external reference (e.g., low quality, unreliability - Olshavsky and Kumar 2001).

\section{Performance evaluations}

It has been shown that brand strength positively affects performance evaluation of a product (Brown and Dacin 1997, Spreng, MacKenzie, and Olshavsky 1996). While these are important and interesting findings, they do not address the phenomenon that becomes more probable in durable goods as the technological sophistication of products increases - the product failure (Petroski 2003). If the aspect of performance has a clear reference point (missing in Spreng, MacKenzie, and Olshavsky's 1996 study of camcorder performance) or has an unequivocal consequence, I would expect stronger dissatisfaction with a product with stronger brand compared to a weaker brand, again putting a stronger brand at a disadvantage. The tendency of people to give more attention to such phenomena, and for them to elaborate more on the information that is incongruent to their pre-existing believes is well documented in the incongruency literature (e.g. Mandler 1982, Heckler and Childers 1992, Edwards and Smith 1996). Dissatisfying performance will be incongruent with the perceptions of a strong brand to a larger degree than with those of a weak brand, and therefore will receive more attention and weight, resulting in disproportionate affects on attitudes (Lee and Mason 1999, Meyers-Levy and Tybout 1989). In investigating this relationship it is important to control for factors that may mask the dissatisfaction, especially self-justification bias if product selection has been done by a customer on the basis of its brand.

P2: Disappointing performance/attributes will have stronger negative effects on the brand equity of a stronger brand than on that of a weaker brand.

\section{Foregone alternatives}

Insights into the role of forgone alternatives in the consumer's evaluation of a purchase promise additional explanations of possible negative effects of strong brand equity.

The magnitude of dissatisfaction with a branded product can increase significantly in the presence of feedback about the performance of forgone alternatives. The model of post-choice evaluation proposed by Inman, Dyer and Jia (1997) suggests that when foregone alternatives from the consideration set perform better than the chosen product, knowledge about this negatively impacts the post-choice evaluation of the product (and the brand associated with it). Therefore, we can expect that if a better performing forgone alternative had a weaker brand, the negative impact on the selected product's evaluation will be stronger than in a case where the forgone alternative had a stronger brand. The possibility of a consumer becoming aware of the performance of forgone alternatives is very real nowadays. The fact that consumers attend to product related information after the purchase has long been established (see Donnely and Ivancevich 1970 for the review). Comparative information about product performance 
is easily available from the Internet or printed media, and often similar products owned by peers and friends can be observed. With moderate involvement in a purchase, the consumer may skip searching for such information before the purchase, but can easily run across it afterwards.

P3: The negative impact on brand equity of dissatisfaction with a product's performance in the presence of information about comparable or better performance of foregone alternative (s) is going to be greater for stronger brands than for weaker brands.

Related to the possibility of finding out about the foregone alternative's performance are considerations involved in product choice. The feeling of regret can be induced by a consumer's failure to switch from a preferred brand (a strong brand in a consumer's mind) to the one that he knew performed better. Inman and Zeelenberg (2002) demonstrated that although traditionally stronger feelings of regret are associated with action (switching) than inaction (staying loyal), this relationship is in fact moderated by the justifiability of the decision. If the decision to stay loyal is not justified, regret will be stronger than in the case of a justified switch. This indicates the possibility of consumer loyalty - one of manifestations of brand equity (Aaker 1991) - to lead to stronger post-purchase regret and subsequently to negative impact on brand equity.

P4: The negative impact of consumer dissatisfaction on brand equity will be larger if product selection has been done based upon brand name while ignoring product attributes.

\section{Considerations of Fairness}

Initially brought up in the economics literature (Kahneman, Knetch, and Thailer 1986), the notion of fairness implies that customers tend to resist unfair behaviors by market players and to punish unfair actors even at some cost to themselves. Fournier (1998) suggested extending the notion of brand loyalty - one of the manifestations of consumer-based brand equity - into the domain of consumer-brand relationships. One of the cornerstones of successful and lasting relationship is a perception of fair behavior of partners (Fournier 1998, Schultz 2000).

In marketing, studies of unfair behaviors focus mostly on price increase (Campbell 1999, Kaufmann, Ortmeyer, and Smith 1991). But it is logical to expect that behaviors leading to the ability to hike prices may be perceived by customers as unfair or predatory. A number of studies suggest that strong brand equity allows a brand to command price premiums (Park and Srinivasan 1994, Simon 1979). This is especially common when the brand gains significant power and starts to dominate the market. Yet, total or nearly total market domination, preventing customers from switching, coupled with price increases and reductions in service levels can create in consumers a feeling of being hostages to a major brand (e.g., Microsoft), leading to the perception of a brand as being unfair. Therefore, even when a brand enjoys ultimate strength, dominating the market, it is possible that customers would be in a constant search for substitutes, eager to disassociate themselves from the brand they perceive as unfair. This creates a cap to a brand's ability to recoup investments in achieving market domination, and also puts it in an unfavorable position in the face of new entrants (e.g. Triumph motorcycles, Haig 2003).

P5: The market moves of the brand dominating the market will be perceived as less fair than the moves of a brand sharing the market with relatively equal competitors.

While customers may continue to purchase the brand that they perceive as unfair because of the absence of adequate substitutes, their commitment to such a brand is not going to be high. Based on the literature on biased assimilation and impression formation, Ahluwalia, Burnkrant and Unnava (2000) hypothesized that negativity effect is qualified by the level of consumer's commitment to the brand. With high commitment to the brand, cognitive dissonance processes are hypothesized to take precedence over the diagnosticity of negative information, and such information has a lesser impact on consumer attitudes towards the brand. With low commitment, though, negative information receives higher weight in customer's evaluation of the brand. Because of the lower commitment to the brand perceived as unfair, customers are more likely to focus more on the negative information about the brand and to incorporate it into their attitude towards the brand. 
P6: Negative information has a stronger negative impact on the brand perceived as unfair as opposed to the brand perceived as fair.

\section{Brand Management Perspective}

While some troubles for strong brands may be caused by shifts in customer attitudes or by competitor actions (that is to say they may originate outside the firm) it is quite possible that others can come from inside. Firms (specifically, their managers) can and often do harm to themselves by making and carrying out sub-optimal strategic decisions. Numerous studies show that managers are not objective decision makers who would react to market conditions in an impartial and unbiased manner (e.g., Alderson and Betker 2003, Key 2002, Garbade 1999, Walsh 1988, Day and Nedungadi 1994) but rather rely on what is commonly known as "managerial intuition", and is defined as "heuristics and biases" (Kahneman and Tversky 1996) or "managerial belief structures" (Walsh 1988) in academic literature. Whenever managerial discretion is involved, there is a potential that idiosyncratic biases may drag decisions away from the optimum. This potential will be higher when decisions are to be made under pressure and more pronounced when balancing certain kinds of activities is involved. One balance that brand managers must keep is between brand-building and brand-leveraging activities (Aaker 1996, Mizik and Jacobson 2003). Consistent deviation from such balance can result in overspending (deviation towards brand-building activities) or in brand equity dilution (deviation towards brand-leveraging strategies).

Based upon the regulatory focus theory advanced in psychology (Higgins 1997, Crowe and Higgins 1997) I would expect to see managers of stronger brands gravitate more towards brand-building activities, and managers of weaker brands (but not startups) towards brand-leveraging. Regulatory focus theory, which can be seen as a further development of a prospect theory (Kahneman and Tversky 1979), posits that depending on the situation, a person can be either in a promotion or in a prevention focus. Promotion focus is associated with aspirations, signifies achievement and fast moving towards tangible goals. Prevention focus is associated with responsibilities, and signifies preserving a status-quo.

Managing a strong brand involves serious responsibilities and requires at least preserving its leading position. The consequences of the potential loss of brand equity are smaller for a weaker brand, while the potential gain from brand leveraging is higher. Therefore, managers of strong brands can be expected to have prevention focus, while managers of weaker brands would have promotion focus. Being in a certain regulatory focus results in automatic (unconscious) preference towards certain strategies (Crowe and Higgins 1997). In a marketing context strategies suitable for managerial prevention focus are those emphasizing brand-building and for promotion focus brand-leveraging. It has to be noted that the issue here is not in one type of strategies being more "correct" than another but in a fact that strategic choices consistently biased in one or another direction can not be optimal. It has also to be noted that the proposed relationship can be changed under certain conditions defined by variables such as resource availability, a firm's culture, its strategic orientation, etc. Also, the behavioral manifestation of such cognitive preferences can be hampered by external factors - very much like other types of behavioral intents. Yet, the existence of a cognitive state which is being influenced by brand equity and which drives managerial decisionmaking away from optimal represents a potential negative effect of strong brand equity and needs serious investigation.

P7: All other things being equal, the state of a brand represented by its brand equity will affect the decision making of brand managers, skewing it towards either predominantly brand-building for strong brands or predominantly brand-leveraging for weaker brands.

\section{Liabilities of Size and Leadership}

Consumers' Perceptions Compliance

Brands are engaged in continuous cycles of re-inventing themselves. Some authors point out the risks of building unrealistic expectations (e.g., Haig 2003), but as the previous discussion shows, expectations may grow uncontrollably. In advocating an economics of information approach to brand equity, Swait, et al. (1993) stated that "reputation may serve as the mechanism that induces firms positioned as 'high quality firms' to actually deliver high 
quality products." (p. 24). Therefore, to preserve the leadership companies have to keep investing in R\&D, market research, and advertising. The efficiency of such investments can be expected to be lower for established brands because of the ceiling effect in the brand equity. It can be expected that after a certain level of brand equity is achieved the results of marketing and R\&D investments will start to diminish (Hotchkiss and Franken 1927). This puts any strong brand at a disadvantage in comparison to a weaker competitor. It is important, though, to acknowledge that returns on $R \& D$ also depend on the learning curve of the $R \& D$ department; therefore experience should be controlled out.

P8: Growth of brand equity per dollar invested in $R \& D$ is larger for a weaker brand as opposed to a stronger brand.

P9: Growth of brand equity per dollar invested in advertisement is larger for a weaker brand as opposed to a stronger brand.

Note that the propositions above do not exactly contradict previous findings that brand equity is driven by advertisement and R\&D (Simon and Sullivan 1993). I just argue that the efficiency of these drivers drops as brand equity grows.

The above propositions may be used to explain some of the instances of strong brands going bankrupt or leaving the market. A highly efficient production system is required to justify inflated R\&D and advertisement expenditures. Production efficiency can be achieved by economies of scale, which by definition should be applicable towards a brand with a larger market share. Types of production do exist though, that do not lend themselves easily to economies of scale. Highly prestigious products with a lot of handiwork (e.g., traditional Rolls-Royce or AstonMartin cars, jewelry, etc.) are extreme examples. In general, any production milieu wherein fixed assets grow at a rate comparable to the production rate is going to be at a disadvantage trying to recoup $\mathrm{R} \& \mathrm{D}$ and marketing investments.

P10: The rate of bankruptcies or of the demise of strong brands will be higher in industries requiring larger fixed assets as compared to industries with lesser requirements.

\section{IMPLICATIONS AND FUTURE RESEARCH}

This discussion only touches the tip of the iceberg of research opportunities related to the negative effects of brand equity and brand decline and failure. Implications of the research in this direction are twofold. For practitioners these findings will outline limitations of brand equity effects and will signal that a more cautious approach is required to building, and especially to appropriating the benefits of the brand equity. For the academic community these findings will signal the existence of new venues within which to expand our knowledge of brand equity effects. Suggested relationships only exist under a limited set of conditions and uncovering other pieces of the puzzle should be the goal of the future research.

Following Golder's (2000) proposition to use historical method in marketing research, more evidence of brand performance over time has to be collected and analyzed. More in-depth study of brand mortality rates is warranted to compare brands with strong and weaker equities. The study done by Golder (2000) is limited by the way the initial 1923 study has been conducted, focusing on strong brands only. Using archival data and a shorter time span it is possible to assess brands in different brand equity tiers. Exploratory studies of brand decline should yield another important outcome - the creation of brand demise typology, accounting for various phenomema that may have been the source(s) of trouble for any given brand.

A lot can be borrowed from the strategic management literature where studies of the demise and failure of firms have been conducted for some time now (Daily 1994). One promising field is interaction of top management teams with brands. What is the effect of a manager's personal attachment to the brand? What sort of backgrounds make better brand managers? All these questions are directly tied to brand success or mortality.

In studying secondary data, it would be interesting to look into how differently stronger and weaker brands react to increases and decreases in marketing mix elements. If research will demonstrate that a decrease in marketing 
mix variables has a more adverse effect on stronger brand, such finding will support the notion of the spendings cycle that strong brands find themselves involved in.

An important part of the stream of brand equity research should be in disentangling consumer-based brand equity from the ability of the firm to realize the benefits of it and the strategies involved in attending to these goals. One can expect that only a limited choice of strategies for leveraging existing brand equity is available in certain industries. Although not directly related to brand equity adverse effects, this information will assist in the creation of more refined secondary measures of consumer-based brand equity based on its outcomes for the firm.

\section{CONCLUSIONS}

This paper attempts to justify the need for a dedicated stream of research within marketing that will strive to uncover causes of brand failure and demise. Strong brands are not invincible: they often lose their leading positions and sometimes leave the market. As of now there exist very few studies that shed light on the process of brand decline and on the negative effects of brand equity. Such incomplete coverage is unacceptable.

Strong brands are subject to threats that are common to all market players, but they also are prone to threats that arise from their status as market leaders, from consumer perceptions and the associations embodied in their collective memories. Strong brand owners can also become victims of a prisoner's dilemma when their strategic actions are dictated by the need to protect investments in brand-building made earlier. All these conditions can be investigated in empirical studies. "Studies which focus exclusively on surviving firms potentially bias research findings and may do little to inform the failure process." (Daily 1994, p. 285). This formula can and should be applied to the field of brand equity as well.

\section{AUTHOR INFORMATION}

Dr. Alexander Rusetski received his Ph.D in Marketing from Indiana University, USA in 2007. He is currently an Assistant Professor of Marketing at the School of Administrative Studies, York University, Toronto. Dr. Rusetski's research focuses on marketing strategy and managerial decision-making, and his studies were published in the Journal of International Business Studies, Journal of Strategic Marketing, Journal of Business and Economic Research and presented at several conferences. E-mail: arusetsk@yorku.ca.

\section{REFERENCES}

1. $\quad$ Aaker, David A. (1991), Managing Brand Equity. New Yourk, N.Y.: Free Press.

2. (1996), Building Strong Brands, New York, NY: Free Press.

3. Ahluwalia, Rohini, Robert E. Burnkrant, and H.R.Unnava (2000), "Consumer Response to Negative Publicity: The Moderating Role of Commitment.” Journal of Marketing Research, Vol. XXXVII (May), 203-14.

4. Alderson, Michael J. and Brian L. Betker (2003),"Managerial Discretion Costs and the Acquisition of Capital." Financial Management, 32 (1), p109-127.

5. Broniarczyk, Susan M., and Andrew D. Gershoff (2003), "The Reciprocal Effects of Brand Equity and Trivial Attributes." Journal of Marketing Research, Vol. XL (May), 161-175.

6. Brown, Tom J., and Peter Dacin (1997), "The Company and the Product: Corporate Associations and Consumer Product Responces." Journal of Marketing 61 (1), 68-84.

7. Campbell, Margaret C. (1999), "Perceptions of Price Unfairness: Antecedents and Consequences." Journal of Marketing Research, Vol. XXXVI (May), 187-199.

8. Crowe, Ellen and E. Tory Higgins (1997), "Regulatory Focus and Strategic Inclinations: Promotion and Prevention in Decision-Making," Organizational Behavior and Human Decision Processes, 69 (2), 117 132.

9. Daily, Catherine M. (1994), "Bankruptcy in Strategic Studies: Past and Promise", Journal of Management, Vol. 20, No. 2, 263-295.

10. Day, George S. and Prakash Nedungadi (1994), "Managerial Representations of Competitive Advantage," Journal of Marketing, 58 (April), 31-44. 
11. Donnely, James H. and John M. Ivancevich (1970), "Post-Purchase Reinforcement and Back-Out Behavior." Journal of Marketing Research, Vol. VII (August), 399-400.

12. Dorner, Dietrich (1996), The logic of failure: recognizing and avoiding error in complex situations, Reading, Mass.: Perseus Books.

13. Edwards, Kari and Edward E. Smith (1996), "A Disconfirmation Bias in the Evaluation of Arguments," Journal of Personality and Social Psychology, 71 (1), 5-24.

14. Erdem, Tulin, and Joffre Swait (1998), "Brand Equity as a Signaling Phenomenon.” Journal of Consumer Psychology, 7 (2), 131-157.

15. Fieldwick, Paul (1996), "What Is Brand Equity Anyway, and How to Measure it?" Journal of Market Research Society, Vol. 38, 2 (April), 85-104.

16. Fournier, Susan (1998), "Consumers and Their Brands: Developing Relationship Theory in Consumer Research.” Journal of Consumer Research, Vol. 24 (March), 343-373.

17. Garbade, Kenneth D (1999), "Managerial Discretion and Contingent Valuation of Corporate Securities." Journal of Derivatives, 6 (4), p65-77

18. Golder, Peter N. (2000), "Historical Method in Marketing Research with New Evidence on Long-Term Market Share Stability", Journal of Marketing Research, Vol. XXXVII (May), 156-172.

19. Haig, Matt (2003), Brand Failures, Kogan Page

20. Heckler, S. E., and T. L. Childers (1992), "The Role of Expectancy and Relevancy in Memory for Verbal and Visual Information: What Is Incongruency?" Journal of Consumer Research, 18, 475-492.

21. Higgins, E. Tory (1997), "Beyond Pleasure and Pain," American Psychologist, 52 (December), 1280-1300.

22. Hotchkiss, George Burton and Richard B. Franken (1927), "The Measurement of Advertising Effects." Harper and Brothers, NY.

23. Inman, J. Jeffrey, James S. Dyer, and Jianmin Jia (1997), “A Generalized Utility Model of Disappointment and Regret Effects on Post-Choice Valuation.” Marketing Science, Vol. 16 (2), 97-111.

24. and Marcel Zeelenberg (2002), "Regret in Repeat Purchase versus Switching Decisions: The Attenuating Role of Decision Justifiability." Journal of Consumer Research, Vol. 29 (June), 116-128.

25. Kahneman, Daniel, Jack L. Knetsch, and Richard H. Thaler (1986), "Fairness and the Assumptions of Economics." Journal of Business, 59 (4-2), S285-S300.

26. and Amos Tversky (1979), "Prospect Theory: An Analysis of Decision under Risk," Econometrica, 47(2), 263-291.

27. (1996), "On the Reality of Cognitive Illusions," Psychological Review, 103 (3), $582-591$.

28. Kaufmann, Patrick J., Gwen Ortmeyer, and N. Craig Smith (1991), "Fairness in consumer pricing." Journal of Consumer Policy, Vol. 14 (2), 117-141.

29. Keller, Kevin Lane (1993), "Conceptualizing, Measuring, and Managing Customer-Based Brand Equity." Journal of Marketing, Vol. 57 (1) (January), 1-22.

30. (2002), Branding and Brand Equity. Cambridge, Massachusetts: Marketing Science Institute.

31. Key, Susan (2002), "Perceived Managerial Discretion: An Analysis Of Individual Ethical Intentions." Journal of Managerial Issues, 14 (2), p218-234.

32. Kirmani, Amna and Akshay R. Rao (2000), "No Pain, No Gain: A Critical Review of the Literature on Signaling Unobservable Product Quality." Journal of Marketing, Vol. 64 (April), 66-79.

33. Lee, Y. W., \& Mason, C. (1999). Responses to information incongruencey in advertising: the role of expectancy, relevancy, and humor. Journal of Consumer Research, 26 (September), 156-169.

34. Mandler, George (1982), "The Structure of Value: Accounting for Taste," in Affect and Cognition: The Seventeenth Annual Carnegie Symposium on Cognition, ed. M. S. Clark and S. T. Fiske, Hillsdale, NJ: Lawrence Erlbaum Associates, Inc, 3-36.

35. Meyers-Levy Joan and Alice M. Tybout (1989), "Schema Congruity as a Basis for Product Evaluation," Journal of Consumer Research, 16 (June), 39-54.

36. Mizik, Natalie and Robert Jacobson (2003), "Trading off between Value Creation and Value Appropriation: The Financial Implications of Shifts in Strategic Emphasis," Journal of Marketing, 67 (January), 63-76.

37. Oliver, Richard L (1999), "Whence consumer loyalty?” Journal of Marketing, Vol 63(Special Issue), 3344. 
38. Olshavsky, Richard W. and Anand Kumar (2001), "Revealing the Actual Roles of Expectations in Consumer Satisfaction with Experience and Credence Goods." Journal of Consumer Satisfaction, Dissatisfaction and Complaining Behavior, Vol. 14, 60-73.

39. Park, Chan Su and V. Srinivasan (1994), "A Survey-Based Method for Measuring and Understanding Brand Equity and its Extendability." Journal of Marketing Research, 31 (May), 271-88.

40. Petroski, Henry (2003), Small Things Considered: Why There Is no Perfect Design. Alfred A. Knopf, New York.

41. Porter, M.E. (1985), Competitive Advantage: Creating and Sustaining Superior Performance. New York, NY: Free Press.

42. Purohit, Devavrat, and Joydeep Srivastava (2001), "Effect of Manufacturer Reputation, Retailer Reputation, and Product Warranty on Consumer Judgements of Product Quality: A Cue Diagnosticity Framework." Journal of Consumer Psychology, 10 (3), 123-34.

43. Rao, Akshay R., Lu Qu, and Robert W. Ruekert (1999), "Signaling Unobservable Product Quality Through a Brand Ally.” Journal of Marketing Research, Vol. XXXVI (May), 258-268.

44. Schultz, Don E. (2000), "Understanding and Measuring Brand Equity", Marketing Management, Vol. 9 Issue 1 (Spring), p8-9.

45. Simon, Carol J., and Mary W. Sullivan (1993), "The Measurement and Determinants of Brand Equity: A Financial Approach”, Marketing Science, Vol. 12, 1, 28-52.

46. Simon, Hermann (1979), "Dynamics of Price Elasticity and Brand Life Cycles: An Empirical Study." Journal of Marketing Research, 16 (November), 439-52.

47. Spreng, Richard A., Scott B. MacKenzie, and Richard W. Olshavsky (1996), "A Reexamination of the Determinants of Consumer Satisfaction.” Journal of Marketing, Vol. 60 (July), 15-32.

48. Sujan, Harish (1986): "Smarter Versus Harder: An Exploratory Attributional Analysis of Salespeople's Motivation", Journal of Marketing Research, Vol. XXIII (February), 41-49

49. Swait, Joffre, Tulin Erdem, Jordan Louviere, and Chris Dubelaar (1993), "The Equalization Price: A Measure of Consumer-Perceived Brand Equity." International Journal of Research in Marketing, Vol. 10 (1), 23-45.

50. Walsh, James P. (1988), "Selectivity and selective perception: An investigation of managers' belief structures and information processing," Academy of Management Journal, 31(4), 873-896

51. Weiner, Bernard (2000), “Attributional Thoughts about Consumer Behavior.” Journal of Consumer Research, Vol. 27 (December), 382-387.

52. Woods, Robert J. (1998), “Can there be a Common Definition for Brand Equity?” Journal of Modern Business. 
NOTES 